\title{
Budget Impact of Adding Ivabradine to Standard of Care in Patients with Chronic Systolic Heart Failure in the United States
}

\author{
Jeffrey S. Borer, MD; Anuraag R. Kansal, PhD; Emily D. Dorman, MPH, MBA; Stanimira Krotneva, MSc; \\ Ying Zheng, MHSA, MS; Harshali K. Patel, MS, PhD; Luigi Tavazzi, MD; Michel Komajda, MD; \\ lan Ford, PhD; Michael Böhm, MD, PhD; and Adrian Kielhorn, MBA
}

\begin{abstract}
BACKGROUND: Heart failure (HF) costs $\$ 21$ billion annually in direct health care costs, $80 \%$ of which is directly attributable to hospitalizations. The SHIFT clinical study demonstrated that ivabradine plus standard of care (SoC) reduced HF-related and all-cause hospitalizations compared with SoC alone. OBJECTIVE: To estimate the budget impact of ivabradine from a U.S. commercial payer perspective.
\end{abstract}

METHODS: A budget impact model estimated the per-member-per month (PMPM) impact of introducing ivabradine to existing formularies by comparing a reference scenario $(\mathrm{SoC})$ and a new drug scenario (ivabradine $+\mathrm{SoC}$ ) in hypothetical 1 million-member commercial and Medicare Advantage plans. In both scenarios, U.S. claims data were used for the reference cumulative annual rates of hospitalizations (HF, non-HF cardiovascular [CV], and non-CV), and hospitalization rates were adjusted using SHIFT data. The model controlled for mortality risk using SHIFT and U.S. life table data, and hospitalization costs were obtained from U.S. claims data: HF-related $=\$ 37,507$; non-HF CV $=\$ 28,951$; and non-CV $=\$ 17,904$. The annualized wholesale acquisition cost of ivabradine was $\$ 4,500$, with baseline use for this new drug at $2 \%$, increasing $2 \%$ per year.

RESULTS: Based on the approved U.S. indication, approximately 2,000 commercially insured patients from a 1 million-member commercial plan were eligible to receive ivabradine. Ivabradine resulted in a PMPM cost savings of $\$ 0.01$ and $\$ 0.04$ in years 1 and 3 of the core model, respectively. After including the acquisition price for ivabradine, the model showed a decrease in total costs in the commercial (\$991,256 and $\$ 474,499$, respectively) and Medicare populations $(\$ 13,849,262$ and $\$ 4,280,291$, respectively) in year 1 . This decrease was driven by ivabradine's reduction in hospitalization rates. For the core model, the estimated pharmacy-only PMPM in year 1 was $\$ 0.01$ for the commercial population and $\$ 0.24$ for the Medicare Advantage population.

CONCLUSIONS: Adding ivabradine to SoC led to lower average annual treatment costs. The negative PMPM budget impact indicates that ivabradine is an affordable option for U.S. payers.

J Manag Care Spec Pharm. 2016;22(9):1064-71

Copyright $\odot 2016$, Academy of Managed Care Pharmacy. All rights reserved.

\section{What is already known about this subject}

Ivabradine reduces hospitalizations in patients with heart failure (HF). As per FDA approval, ivabradine is indicated to reduce the risk of hospitalization for worsening HF in patients with stable, symptomatic, moderately severe to severe chronic systolic HF, who are in sinus rhythm with resting heart rate $\geq 70$ beats per minute and are on maximally tolerated doses of beta blockers.

\section{What this study adds}

This is the first study to assess the budget impact of introducing ivabradine into the United States from a payer perspective.

The addition of ivabradine to treatment regimens in patients who meet the FDA-approved indication for drug use can be confidently expected to generate lower costs for projected health benefits than if ivabradine was not used.

$\mathrm{H}$ eart failure (HF) affects approximately 5.7 million Americans, and the risk for developing HF increases with age. ${ }^{1,2}$ Prognosis for patients with HF remains relatively poor, with the 5 -year survival rate estimated to be approximately $50 \%{ }^{3}$ In addition, HF is associated with a substantial economic burden because patients require frequent hospitalization, especially those with severe HF not controlled by standard medication. ${ }^{4}$ In 2010, direct medical costs associated with HF in the United States were estimated to be approximately $\$ 21$ billion, $80 \%$ of which was directly attributable to hospitalizations. ${ }^{1,5}$

Relatively high resting heart rate is an indication of inadequate HF control and is an independent predictor of cardiovascular (CV)-related morbidity (hospitalizations) and mortality in patients with left ventricular systolic dysfunction and chronic symptomatic HF. ${ }^{6-10}$ In April 2015, the U.S. Food and Drug Administration approved ivabradine to reduce the risk of hospitalization for worsening of HF in patients with stable, symptomatic, chronic HF with left ventricular ejection fraction $(\mathrm{LVEF}) \leq 35 \%$, who are in sinus rhythm with a resting heart rate $\geq 70$ beats per minute (bpm), and either are receiving maximally tolerated doses of or have a contraindication to beta blockers. Because of the economic burden of HF, the objective of this study was to estimate the budget impact of introducing ivabradine into the formulary from a U.S. payer perspective.

\section{Methods}

\section{Model Overview}

A Microsoft Excel-based budget impact model (Figure 1) was developed to compare a reference scenario, which consisted of the current standard of care (SoC), with a new drug scenario in which ivabradine was added to the current SoC. The analysis was based on a hypothetical 1 million-member U.S. plan 
FIGURE 1 Overview of Budget Impact Model for Ivabradine in U.S. Patients with Heart Failure in Commercial or Medicare Advantage Plans

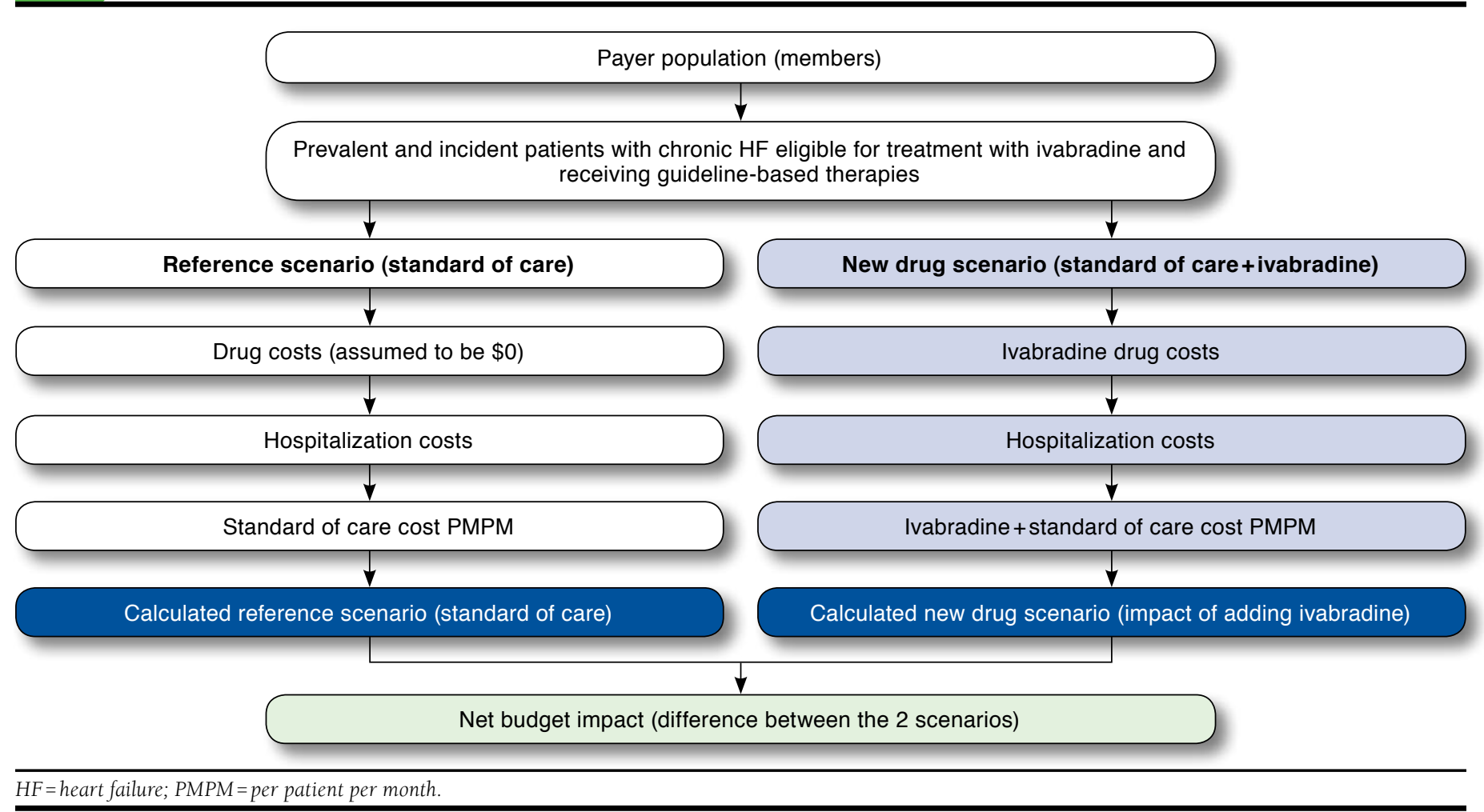

with a commercial population (aged 19-64 years) or Medicare Advantage population (generally aged $\geq 65$ years). Analytically, the model used the frequency and cost of hospitalizations of U.S. patients with HF and applied an ivabradine-driven hospitalization reduction factor derived from the Systolic Heart Failure Treatment with the I(f) Inhibitor Ivabradine Trial (SHIFT). ${ }^{8}$ The reduction in hospitalization costs and drug costs in the reference and new drug scenarios were then compared to assess the overall budget impact of ivabradine, expressed as incremental cost per member per month (PMPM). The model aimed to evaluate how much of the cost of adding ivabradine to SoC was offset by reductions in the cost of hospitalizations.

Two versions of the model were developed: (1) a core model calculated the budget impact of adding ivabradine to SoC by considering only the effect of ivabradine on costs associated with hospitalization for worsening $\mathrm{HF}$ and the cost of ivabradine and (2) an expanded model included all of the elements of the core model, as well as the impact of ivabradine on all-cause hospitalization and the costs of treating adverse events (AE) related to ivabradine treatment. Both versions of the model included the natural death rate of patients in this population based on the SHIFT SoC arm, supplemented with data from the 2010 U.S. life tables and an analysis of mortality rates in patients with HF.11,12 The core and the expanded models were designed to estimate budget impact up to 5 years in the future. For the purpose of simplicity and balance, this article reports the results for year 1 and year 3 .

\section{Model Inputs and Assumptions}

Ivabradine Utilization Expectation. Based on projected drug utilization rates, the model used a utilization rate of $2 \%$ in year 1 within the eligible patient population, with a $2 \%$ absolute increase for each subsequent year.

Epidemiology. The model generated separate results for the commercial and Medicare Advantage populations. A retrospective database analysis was conducted using the Optum research database (Optum, Eden Prairie, MN) to estimate demographics, annual cumulative hospitalization rates, and hospitalization costs for the 2 populations. In the commercial population, the mean age was 63 years, and $43 \%$ were female; in the Medicare Advantage population, the mean age was 77 years, and $54 \%$ were female.

The target eligible patient population for ivabradine was estimated from the literature and was defined as adults (aged $\geq 18$ years) with systolic chronic HF in New York Heart Association (NYHA) Class II, III, or IV and normal sinus rhythm with 
TABLE 1 Epidemiology Parameters for a 1 Million-Member Hypothetical Health Care Plan

Model Population Parameter

Hypothetical plan membership

Prevalence of chronic HF

Chronic HF patients with systolic chronic HF

With normal sinus rhythm

With normal sinus rhythm and NYHA Class II to IV

With normal sinus rhythm and NYHA Class II to IV with heart rate of $\geq 70 \mathrm{bpm}$ Incidence of chronic HF

Chronic HF patients with systolic chronic HF

With normal sinus rhythm

With normal sinus rhythm and NYHA Class II to IV

With normal sinus rhythm and NYHA Class II to IV with heart rate of $\geq 70 \mathrm{bpm}$

Total patients eligible for treatment (prevalent + incident populations)

\begin{tabular}{c|c|c|c}
\multicolumn{2}{c|}{ Commercial Population } & \multicolumn{2}{c}{ Medicare Advantage Population } \\
\hline Frequency, \% & Patients, $\mathbf{n}$ & Frequency, $\%$ & Patients, $\mathbf{n}$ \\
\hline $1.0^{\mathrm{a}}$ & $1,000,000$ & & $1,000,000$ \\
\hline $52.9^{\mathrm{c}}$ & 10,000 & $16.0^{\mathrm{b}}$ & 160,000 \\
\hline $66.8^{\mathrm{d}}$ & 5,290 & $52.9^{\mathrm{c}}$ & 84,640 \\
\hline $88.3^{\mathrm{d}}$ & 3,534 & $66.8^{\mathrm{d}}$ & 56,540 \\
\hline $61.3^{\mathrm{e}}$ & 3,120 & $88.3^{\mathrm{d}}$ & 49,924 \\
\hline 0.1 & 1,913 & $61.3^{\mathrm{e}}$ & 30,604 \\
\hline $52.9^{\mathrm{c}}$ & 1,000 & 3.1 & 31,000 \\
\hline $66.8^{\mathrm{d}}$ & 529 & $52.9^{\mathrm{c}}$ & 16,399 \\
\hline $88.3^{\mathrm{d}}$ & 353 & $66.8^{\mathrm{d}}$ & 10,955 \\
\hline $61.3^{\mathrm{e}}$ & 191 & $88.3^{\mathrm{d}}$ & 9,673 \\
\hline & 2,104 & $61.3^{\mathrm{e}}$ & 5,929 \\
\hline
\end{tabular}

${ }^{a}$ Chamberlain AM, Redfield MM, Alonso A, Weston SA, Roger VL. Atrial fibrillation and mortality in heart failure: a community study. ${ }^{12}$

${ }^{b}$ Centers for Medicare \& Medicaid Services. Chronic conditions among Medicare beneficiaries. Chartbook: 2012 edition. ${ }^{13}$

'Owan TE, Hodge DO, Herges RM, Jacobsen SJ, Roger VL, Redfield MM. Trends in prevalence and outcome of heart failure with preserved ejection fraction. ${ }^{14}$

dFonarow GC, Albert NM, Curtis AB, et al. Improving evidence-based care for heart failure in outpatient cardiology practices: primary results of the Registry to Improve the Use of Evidence-Based Heart Failure Therapies in the Outpatient Setting (IMPROVE HF). ${ }^{15}$

eStudy of Anemia in a Heart Failure Population (STAMINA) registry (N=1,090) from June 24, 2002, to July 11, 2003

bpm = beats per minute; HF = heart failure; NYHA=New York Heart Association.

\section{FIGURE 2 U.S. Patients with Heart Failure Eligible for Ivabradine}

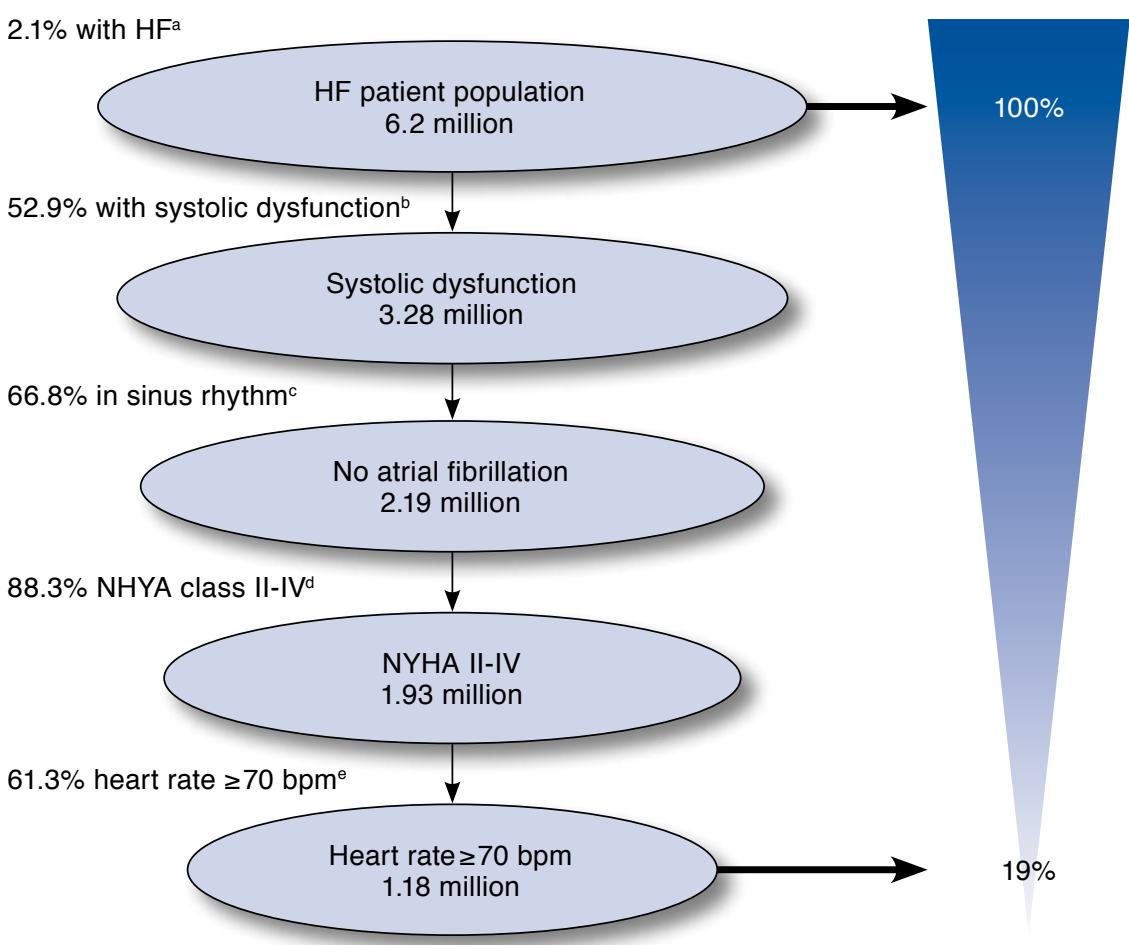

\footnotetext{
a Heidenreich PA, Albert NM, Allen LA, et al. Forecasting the impact of heart failure in the United States: a policy statement from the American Heart Association. ${ }^{5}$

${ }^{b}$ Centers for Medicare E Medicaid Services. Chronic conditions among Medicare beneficiaries. Chartbook: 2012 edition. October 2012. ${ }^{13}$

'Study of Anemia in a Heart Failure Population (STAMINA) registry (N=1,090) from June 24, 2002, to July 11, 2003.

dChamberlain AM, Redfield MM, Alonso A, Weston SA, Roger VL. Atrial fibrillation and mortality in heart failure: a community study. ${ }^{2}$

'Optum research analysis by authors, November 5, 2013.

bpm = beats per minute; $H F=$ heart failure; NYHA = New York Heart Association.
} 
TABLE 2 Hospitalization, Mortality, and AE Rates for Patients with Chronic Systolic HF by Data Source

\begin{tabular}{|c|c|c|c|c|c|}
\hline \multirow[b]{2}{*}{ Parameter } & \multicolumn{2}{|c|}{ U.S. Claims Data } & \multicolumn{3}{|c|}{ SHIFT Datab } \\
\hline & Commerciala $^{\mathrm{a}}$ & $\begin{array}{c}\text { Medicare } \\
\text { Advantage }^{\mathrm{a}}\end{array}$ & $\begin{array}{l}\text { Placebo }+ \\
\text { SoC }\end{array}$ & $\begin{array}{l}\text { Placebo }+ \\
\text { Ivabradine }\end{array}$ & $\begin{array}{l}\text { Incident Rate Ratios } \\
(95 \% \mathrm{CI})^{\mathrm{c}}\end{array}$ \\
\hline \multicolumn{6}{|l|}{ Hospitalizations } \\
\hline HF-related (base case) & 0.928 & 1.144 & 0.204 & $0.151^{\mathrm{d}}$ & $0.75(0.65-0.87)$ \\
\hline Non-HF CV-related (sensitivity analysis) & 0.070 & 0.093 & 0.179 & $0.169^{\mathrm{d}}$ & $0.95(0.84-1.07)$ \\
\hline Non CV-related (sensitivity analysis) & 0.524 & 0.645 & 0.142 & $0.126^{\mathrm{d}}$ & $0.88(0.75-1.04)$ \\
\hline \multicolumn{6}{|l|}{ Mortality } \\
\hline HF-related & - & - & 0.026 & $0.019^{\mathrm{d}}$ & $0.74(0.58-0.94)$ \\
\hline Non-HF CV-related & - & - & 0.057 & $0.056^{\mathrm{d}}$ & $0.98(0.84-1.14)$ \\
\hline \multicolumn{6}{|l|}{ AEs (alternative scenario analyses), \% } \\
\hline Asymptomatic bradycardia & - & - & 0.8 & 3.6 & \\
\hline Symptomatic bradycardia & - & - & 0.6 & 2.9 & \\
\hline Atrial fibrillation & - & - & 4.6 & 5.8 & \\
\hline Phosphenes & - & - & 0.1 & 0.4 & \\
\hline Blurred vision & - & - & 0.3 & 1.8 & \\
\hline \multicolumn{6}{|c|}{$\begin{array}{l}\text { aptum research data analysis by authors, November } 5,2013 . \\
\text { bSwedberg K, Komajda } \mathrm{M}, \text { Bohm } \mathrm{M} \text {, et al. Ivabradine and outcomes in chronic heart failure (SHIFT): a randomised placebo-controlled study. }{ }^{8} \\
\text { cIncident rate ratios represent placebo + ivabradine versus placebo }+ \text { SoC. } \\
\text { dIvabradine rates are presented for exemplary purposes but are not used as inputs in the model. } \\
\text { AE=adverse event; } C I=\text { confidence interval; } C V=\text { cardiovascular; } H F=\text { heart failure; SoC=standard of care. }\end{array}$} \\
\hline
\end{tabular}

a heart rate of $\geq 70 \mathrm{bpm}$. The target population sizes were calculated as the sum of prevalent and incident cases in the U.S. commercial and Medicare populations estimated using multiple inputs, such as NYHA Class and heart rate (Table 1 and Figure 2), ${ }^{5,13-15}$ The epidemiological makeup of the target population was assumed to remain constant across the model time horizon, consistent with American Heart Association methodology. ${ }^{5}$

Clinical Inputs. Ivabradine efficacy was derived using data from SHIFT, in which 6,505 patients with moderate-to-severe (NYHA Class II, III, or IV) HF in normal sinus rhythm, with $\mathrm{LVEF} \leq 35 \%$ and heart rate $\geq 70 \mathrm{bpm}$, and with an HF-related hospitalization within the past year were randomized to ivabradine or placebo in addition to maximally tolerated beta blockers and other guideline-suggested drug therapies. ${ }^{8}$ The model had the ability to use annualized hospitalization rates either from clinical trial data (SHIFT) or real-world U.S. claims (Optum claims). The results obtained using real-world U.S. hospitalization rates are reported in this article. The mortality inputs used in this model reflect natural death rates (Table 2). To align with ivabradine's U.S. label, mortality benefit because of use of ivabradine was not considered in this model.

To derive clinical inputs for patients treated with ivabradine in the new drug scenario, hospitalization rates from the reference case were adjusted based on treatment effect data derived from a post hoc analysis of the SHIFT trial population (incident rate ratio $=0.75$ over the duration of the entire trial [median $=22.9$ months] $).{ }^{10}$ For the expanded model, which included all-cause hospitalization, annualized incidence rates for each type of hospitalization were calculated using the intent-to-treat set as the total number of events divided by the total number of patient-years at risk (from randomization until death or the end of study, whichever came first). The model calculated mutually exclusive hospitalization rates and costs for HF-related, non-HF CV-related, and non-CV-related hospitalizations to avoid double counting events that could occur if the overlapping categories of "all-cause" and "CV-related" were used. Mortality benefit as a result of adding ivabradine to SoC was not included in either model.

Cost Inputs. Because ivabradine is intended to be used as an add-on therapy and not expected to affect the use of SoC, the costs of SoC drugs were excluded from the model. Hospitalization cost inputs were calculated from the Optum research database for both populations. InGauge data that included commercial fee ranges and geographic adjustment factors were used for AE-related costs (Table 3). ${ }^{16}$ The hospitalization costs were estimated separately for the commercial and Medicare Advantage populations. All hospitalization cost inputs were based on insurer-paid claims and did not include patient out-of-pocket costs or adjustment for coordination of benefits among more than 1 insurer. ${ }^{13,17}$ Therefore, the cost of hospitalization used in this model may not reflect the total cost. The cost for ivabradine was $\$ 4,500$ per year for every patient included in the model-the wholesale acquisition cost as of April 15, 2015. 


\section{TABLE 3 Cost Inputs in U.S. Dollars}

\begin{tabular}{|c|c|c|}
\hline Cost Input & Commercial Population (\$) & Medicare Advantage Population (\$) \\
\hline Ivabradine acquisition, cost per year & 4,500 & 4,500 \\
\hline \multicolumn{3}{|l|}{ Hospitalization, cost per event } \\
\hline HF-related (core model) & 37,507 & 22,956 \\
\hline Non-HF CV-related (expanded model) & 28,951 & 18,127 \\
\hline All-cause (expanded model) & 17,904 & 11,489 \\
\hline \multicolumn{3}{|l|}{$\mathrm{AE}$, cost per event (alternative scenario) ${ }^{\mathrm{a}}$} \\
\hline Asymptomatic bradycardia & $142^{b}$ & $73^{e}$ \\
\hline Symptomatic bradycardia & $686^{c}$ & $367^{\mathrm{f}}$ \\
\hline Atrial fibrillation & $686^{c}$ & $367^{\mathrm{f}}$ \\
\hline Blurred vision & $187^{\mathrm{d}}$ & $126 \mathrm{~g}$ \\
\hline Phosphenes & $187^{\mathrm{d}}$ & $126 \mathrm{~g}$ \\
\hline \multicolumn{3}{|c|}{ 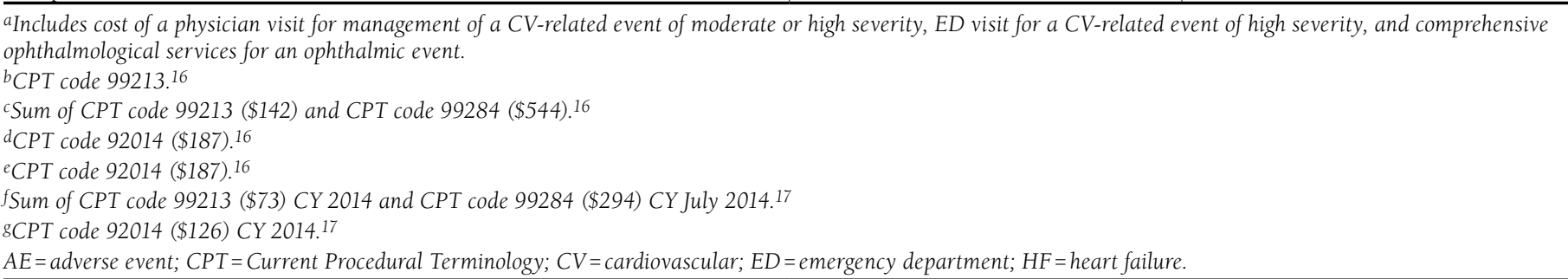 } \\
\hline
\end{tabular}

The expanded model included a wider scope of the additional inputs related to the cost of all-cause hospitalization and AEs. Costs associated with non-HF CV-related and nonCV-related hospitalizations were estimated from the Optum research database. Using the SHIFT safety dataset, rates of AEs for the reference and new drug scenarios were calculated as the total number of AEs divided by the number of patient years at risk. AEs included in the model were asymptomatic bradycardia, symptomatic bradycardia, atrial fibrillation, phosphenes, and blurred vision. These AEs were selected because, in SHIFT, they were among the most frequent AEs overall, and the incidence differed between the ivabradine and placebo arms; in addition, they are potentially related to ivabradine's mechanism of action. ${ }^{8}$ Costs of AE management included cost of outpatient physician visits or emergency department visits for cardiac events of moderate or high severity and cost of comprehensive ophthalmological services for ophthalmic events. ${ }^{17}$

\section{Sensitivity Analyses}

Multiple one-way sensitivity analyses were conducted to understand the impact of varying core model inputs and assumptions on the results (Table 4). In accordance with the International Society for Pharmacoeconomics and Outcomes Research guidance on budget impact analyses, ${ }^{18}$ alternative scenarios of potential interest to payers were tested using the expanded model, which considered the budget impact of all-cause hospitalizations and AEs in addition to HF-related hospitalizations.

\section{Results}

\section{Core Model Results}

In a hypothetical 1 million-member plan, 1,913 commercially insured prevalent patients and 191 incident patients $(\mathrm{N}=2,104)$ were eligible to receive ivabradine. Based on the $2 \%$ utilization for year 1, 38 patients would use ivabradine, and this number would increase to 115 patients in year 3. In the U.S. commercial plan population, ivabradine costs at year 3 were estimated to be $\$ 516,757$. Eligible patients treated with SoC would incur an estimated total cost of $\$ 66,616,644$ as a result of HF-related hospitalizations. Patients treated with ivabradine plus SoC would incur an estimated total cost of $\$ 65,625,389$ as a result of fewer HF-related hospitalizations-a cost savings of $\$ 991,256$. After accounting for the cost of providing ivabradine $(\$ 516,757)$, the net result was a savings of $\$ 474,499$, resulting in an incremental cost savings of \$0.04 PMPM compared with the SoC scenario (Table 5).

In the Medicare Advantage population, the introduction of ivabradine resulted in an incremental cost savings of $\$ 0.36$ PMPM compared with the SoC scenario at year 3. The larger favorable budget impact in the Medicare Advantage plan compared with the commercial plan was driven by a combination of higher prevalence and incidence of HF and the higher rates of HF-related hospitalization, which would be expected in this older population (Table 5).

\section{Expanded Model Results}

Including the costs of AE management and all-cause hospitalization in the expanded model still resulted in a PMPM cost 


\begin{tabular}{|c|c|c|c|c|}
\hline Parameter & Core Model Value & SA Value & $\begin{array}{c}\text { Commercial } \\
\text { Incremental Cost } \\
(\mathrm{PMPM}, \$)^{\mathrm{a}}\end{array}$ & $\begin{array}{l}\text { Medicare Advantage } \\
\text { Incremental Cost } \\
(\text { PMPM, \$) }\end{array}$ \\
\hline Data source for hospitalization rates & $\begin{array}{l}\text { U.S. claims; commercial } \\
\text { perspective }\end{array}$ & $\begin{array}{l}\text { SHIFT trial; commercial } \\
\text { perspective }\end{array}$ & 0.02 & 0.59 \\
\hline \multirow[t]{2}{*}{ Time horizon } & \multirow[t]{2}{*}{3 years } & 5 years & $(0.07)$ & $(0.62)$ \\
\hline & & 1 year & $(0.01)$ & $(0.11)$ \\
\hline \multirow{4}{*}{ Ivabradine utilization } & $2 \%$ in year 1 & $1 \%$ in year 1 & \multirow{3}{*}{$(0.02)$} & \multirow{3}{*}{$(0.18)$} \\
\hline & \multirow[t]{3}{*}{$2 \%$ increase each year } & $1 \%$ increase each year & & \\
\hline & & $5 \%$ in year 1 & & \\
\hline & & $5 \%$ increase each year & $(0.10)$ & $(0.89)$ \\
\hline \multirow[t]{2}{*}{ Ivabradine acquisition cost } & \multirow[t]{2}{*}{$\$ 4,500$} & $\$ 3,600$ (20\% decrease) & $(0.05)$ & $(0.52)$ \\
\hline & & $\$ 5,400$ (20\% increase) & $(0.03)$ & $(0.20)$ \\
\hline \multirow[t]{2}{*}{ Hospitalization events } & \multirow[t]{2}{*}{ HF related } & CV related & $(0.04)$ & $(0.37)$ \\
\hline & & All cause & $(0.05)$ & $(0.53)$ \\
\hline
\end{tabular}

savings of $\$ 0.05$ in the commercial and $\$ 0.52$ in the Medicare Advantage populations (Table 5).

\section{Sensitivity Analyses}

Results from one-way sensitivity analyses performed on the core model with the commercial and Medicare Advantage populations are summarized in Table 4 . The use of alternative hospitalization rates from the SHIFT study resulted in an incremental cost increase of \$0.02 PMPM and \$0.59 PMPM for the commercial and Medicare Advantage populations, respectively. These changes were driven by lower overall rates of hospitalization in the SHIFT study relative to U.S. claims data, resulting in smaller cost offsets from prevented hospitalizations (Table 4). Using U.S. claims data, longer model time frames were associated with increasingly favorable budget impacts: extending the time horizon from 3 to 5 years increased incremental cost savings to $\$ 0.07$ PMPM and \$0.627 PMPM for the commercial and Medicare Advantage populations, respectively. Decreasing the time horizon to 1 year reduced cost savings to $\$ 0.01$ PMPM for the commercial and \$0.11 PMPM for the Medicare Advantage populations. Similarly, greater market penetration was associated with increasingly favorable cost savings: a low uptake scenario of $1 \%$ per year resulted in incremental cost savings of $\$ 0.02$ PMPM for the commercial and \$0.18 PMPM for Medicare Advantage populations, whereas a high utilization scenario of $5 \%$ per year resulted in incremental cost savings of $\$ 0.10$ PMPM and \$0.89 PMPM at year 3 for commercial and Medicare Advantage populations, respectively. Decreasing the ivabradine acquisition cost by $20 \%$ increased cost savings to $\$ 0.05$ PMPM and $\$ 0.52$ PMPM, while an increase of 20\% reduced cost savings to $\$ 0.03$ PMPM and \$0.22 PMPM, respectively (Table 4).

\section{Discussion}

The results of this budget impact analysis indicate that the reduced hospitalizations associated with adding ivabradine treatment to SoC in the eligible patient population would result in overall cost savings for U.S. commercial and Medicare Advantage plan formularies. ${ }^{8}$ Cost savings were primarily driven by reductions in HF-related hospitalizations, which offset the costs of ivabradine. Cost offsets were greater in the Medicare Advantage population than in the commercial plan population because of the much greater prevalence of HF and higher rates of HF-hospitalization in the older population represented in the Medicare Advantage database. Together, these findings demonstrate a consistently favorable budget impact in both populations. These data are useful because chronic HF is associated with a relatively high economic burden, and SHIFT demonstrated that for patients with chronic HF with moderateto-severe systolic dysfunction, targeted reduction in heart rate with ivabradine treatment in combination with SoC resulted in significant reductions in hospitalization rates. ${ }^{8}$

The patient populations targeted in these models were as close as possible to those covered by the approved U.S. indication for ivabradine, including patients with and without a previous HF-related hospital admission. This is in contrast to the SHIFT study population, which included admission within the year before study enrollment and $\mathrm{LVEF} \leq 35 \%$ as inclusion criteria. ${ }^{8}$ While the model assumes similar benefits of adding ivabradine treatment in the broader population, a clear benefit of ivabradine in reducing the risk of HF-related hospitalization in patients without a previous admission has not been rigorously established in clinical trials.

Sensitivity analyses showed that for the commercially insured population, the biggest drivers of budget impact were 
TABLE 5 Cost Projections at Year 3 After Hospitalization for the Hypothetical 1 Million-Member Insurance Plans in U.S. Dollars ${ }^{a}$

\begin{tabular}{|c|c|c|c|c|c|c|}
\hline \multirow[b]{2}{*}{ Costs } & \multicolumn{3}{|c|}{ Commercial $(\$)^{\mathrm{b}}$} & \multicolumn{3}{|c|}{ Medicare Advantage $(\$)^{b}$} \\
\hline & $\begin{array}{l}\text { Reference } \\
\text { Scenario }^{c}\end{array}$ & $\begin{array}{l}\text { New Drug } \\
\text { Scenariod }^{\mathrm{d}}\end{array}$ & $\begin{array}{c}\text { Incremental } \\
\text { Difference }\end{array}$ & $\begin{array}{l}\text { Reference } \\
\text { Scenarioc }^{c}\end{array}$ & $\begin{array}{l}\text { New Drug } \\
\text { Scenariod }^{\mathrm{d}}\end{array}$ & $\begin{array}{c}\text { Incremental } \\
\text { Difference }\end{array}$ \\
\hline \multicolumn{7}{|l|}{ Core model } \\
\hline Drug acquisition & 0.00 & 516,757 & 516,757 & 0.00 & $9,568,971$ & $9,586,971$ \\
\hline HF-related hospitalization & $66,616,644$ & $65,625,389$ & $(991,256)$ & $930,729,958$ & $916,880,696$ & $(13,849,262)$ \\
\hline Total costs & $66,616,644$ & $66,142,146$ & $(474,499)$ & $930,729,958$ & $926,449,667$ & $(4,280,291)$ \\
\hline Cost PMPM & 5.55 & 5.51 & $(0.04)$ & 77.56 & 77.20 & $(0.36)$ \\
\hline \multicolumn{7}{|l|}{ Expanded model ${ }^{\mathrm{e}}$} \\
\hline Drug acquisition & 0.00 & 516,757 & 516,757 & 0.00 & $9,568,971$ & $9,568,971$ \\
\hline HF-related hospitalization & $66,616,644$ & $65,625,389$ & $(991,256)$ & $930,729,958$ & $916,880,696$ & $(13,849,262)$ \\
\hline CV-related hospitalization & $70,495,325$ & $69,491,735$ & $(1,003,590)$ & $990,476,165$ & $976,436,910$ & $(14,039,255)$ \\
\hline All-cause hospitalization & $88,451,086$ & $87,320,369$ & $(1,130,717)$ & $1,253,105,598$ & $1,237,206,927$ & $(15,898,671)$ \\
\hline AEs & 71,756 & 75,380 & 3,264 & 713,815 & 750,446 & 36,631 \\
\hline Total costs & $88,522,842$ & $87,912,506$ & $(610,336)$ & $1,253,819,413$ & $1,247,526,344$ & $(6,293,069)$ \\
\hline Cost PMPM & 7.38 & 7.33 & $(0.05)$ & 104.48 & 103.96 & $(0.52)$ \\
\hline \multicolumn{7}{|c|}{$\begin{array}{l}\text { a No discount rate was applied. } \\
\text { bValues in parentheses represents cost savings to the health plan. } \\
\text { cStandard of care. } \\
\text { dIvabradine + standard of care. } \\
\text { eCore model + all-cause hospitalization and effect of AEs. } \\
\text { AE=adverse event; } C V=\text { cardiovascular; } H F=\text { heart failure; PMPM=per member per month. }\end{array}$} \\
\hline
\end{tabular}

hospitalization rates and ivabradine use. Together, these results suggest that the economic benefit of adding ivabradine to SoC will be substantially influenced by access to treatment, particularly in patient populations at progressively higher risk for HF-related admissions.

This is the first study to assess the budget impact of introducing ivabradine into the United States. A separate budget impact analysis by the National Institute for Health and Care Excellence (NICE) in the United Kingdom estimated the total budget impact as approximately $£ 4,400$ per 100,000 individuals. ${ }^{19}$ This moderate budget impact, together with a favorable assessment of the clinical efficacy, resulted in a positive recommendation for ivabradine by NICE in the United Kingdom.

The strength of the current analysis is that it used data from real-world U.S. medical commercial claims to derive hospitalization rates and costs in the commercial and Medicare Advantage populations, thus making the results highly relevant to the target U.S. populations. Similarly, the natural death rates of non-CV mortality were adjusted using data from U.S. life tables to ensure that mortality rates were as relevant to the target population as possible.

\section{Limitations}

It is important to note that the cost of SoC was not included in the model, resulting in underestimation of total treatment costs. However, because ivabradine is intended to be used in addition to SoC, exclusion of these costs does not affect incremental budget impact. Because of data limitations, costs of AE management in the expanded model considered only those costs associated with outpatient and emergency room visits and did not include costs of AE-associated tests, procedures, or medications; this may have led to an underestimate of the total costs associated with AE management. In addition, although the analysis suggested that incremental budget impact was relatively insensitive to $\mathrm{AE}$ cost, some costs related to $\mathrm{AE}$ management may be associated with inpatient visits (e.g., for symptomatic atrial fibrillation). Although these costs would be captured as a component of all-cause hospitalization, they would not be specifically attributed to AE management.

\section{Conclusions}

Inclusion of ivabradine in the formularies of U.S. commercial and Medicare Advantage plans in the United States is estimated to result in a reduction of HF-related hospitalizations that offset the cost of providing ivabradine to patients. From a U.S. payer perspective, the favorable budget impact associated with ivabradine treatment indicates that ivabradine will be an affordable treatment option in both populations. 


\section{Authors}

JEFFREY S. BORER, MD, The Howard Gilman Institute for Heart Valve Diseases and Ronald and Joan Schiavone Cardiovascular Translational Research Institute, State University of New York Downstate Medical Center, Brooklyn and New York, New York. ANURAAG R. KANSAL, PhD, and YING ZHENG, MHSA, MS, Evidera, Bethesda, Maryland. EMILY D. DORMAN, MPH, MBA, and STANIMIRA KROTNEVA, MSc, Evidera, Montreal, Canada. HARSHALI K. PATEL, MS, PhD, and ADRIAN KIELHORN, MBA, Amgen, Thousand Oaks, California. LUIGI TAVAZZI, MD, Maria Cecilia Hospital, GVM Care E Research, and Ettore Sansavini Health Science Foundation, Cotignola, Italy; MICHEL KOMAJDA, MD, Pitié-Salpétrière Hospital, Pierre and Marie Curie University, and IHU ICAN, Paris, France; IAN FORD, PhD, Robertson Centre for Biostatistics, University of Glasgow, United Kingdom; and MICHAEL BÖHM, MD, PhD, Saarland University Hospital, Homberg, Germany.

AUTHOR CORRESPONDENCE: Jeffrey S. Borer, MD, SUNY Downstate Medical Center, 47 E. 88th St., New York, NY 10128. Tel.: 646.456.4454; E-mail: jsborer1@gmail.com.

\section{DISCLOSURES}

This study was funded by Amgen. Patel is employed by Amgen; Kielhorn was employed by Amgen at the time of the study but is no longer affiliated with Amgen. Borer, Böhm, Ford, and Komajda have received scientific support, consultative fees, and/or speakers honoraria from Servier and Amgen in connection with SHIFT, the trial underlying this analysis. Borer also has received consultative fees from Celladon, Pfizer, ARMGO, Cardiorentis, Novartis, and Takeda USA. Kansal, Dorman, Krotneva, and Zheng are employees of Evidera, which was hired to assist with this study. Tavazzi has received research grants and consultation fees from Servier in connection with this study and has had advisory board memberships with Boston Scientific, Servier, Cardiorentis, Medtronic, St. Jude Medical, and CVie Therapeutics.

Study concept and design were contributed by Dorman and Keilhorn, along with the other authors. Tavazzi, Komajda, Ford, Böhm, and Borer oversaw collection of the data. Tavazzi, Komajda, Ford, Böhm, and Borer (along with Karl Swedberg) formed the Executive Committee of SHIFT, the trial underlying this analysis. The manuscript was written by Kansal, along with the other authors, and revised by Borer and Patel, with assistance from the other authors.

\section{ACKNOWLEDGMENTS}

Medical writing support was provided by Eric Bertelsen, PhD, of Fishawack on behalf of Amgen, and editorial support was provided by Janice Carlson, $\mathrm{PhD}$, of Amgen.

\section{REFERENCES}

1. Mozaffarian D, Benjamin EJ, Go AS, et al. Heart disease and stroke statistics - 2015 update: a report from the American Heart Association. Circulation. 2015;131(4):e29-e322. Available at: http://circ.ahajournals.org/ content/131/4/e29.long. Accessed July 9, 2016.

2. Lloyd-Jones DM, Larson MG, Leip EP, et al. Lifetime risk for developing congestive heart failure: the Framingham Heart Study. Circulation. 2002;106(24):3068-72.
3. Roger VL, Weston SA, Redfield MM, et al. Trends in heart failure incidence and survival in a community-based population. JAMA. 2004;292(3):344-50.

4. Dunlay SM, Redfield MM, Weston SA, et al. Hospitalizations after heart failure diagnosis: a community perspective. J Am Coll Cardiol. 2009;54(18):1695-702. Available at: http://www.ncbi.nlm.nih.gov/pmc/ articles/PMC2803107/. Accessed July 9, 2016.

5. Heidenreich PA, Albert NM, Allen LA, et al. Forecasting the impact of heart failure in the United States: a policy statement from the American Heart Association. Circ Heart Fail. 2013;6(3):606-19. Available at: http:// circheartfailure.ahajournals.org/content/6/3/606.long. Accessed July 9, 2016.

6. Fox K, Borer JS, Camm AJ, et al. Resting heart rate in cardiovascular disease. J Am Coll Cardiol. 2007;50(9):823-30.

7. Fox K, Ford I, Steg PG, et al. Heart rate as a prognostic risk factor in patients with coronary artery disease and left-ventricular systolic dysfunction (BEAUTIfUL): a subgroup analysis of a randomised controlled trial. Lancet. 2008;372(9641):817-21.

8. Swedberg K, Komajda M, Bohm M, et al. Ivabradine and outcomes in chronic heart failure (SHIFT): a randomised placebo-controlled study. Lancet. 2010;376(9744):875-85.

9. Böhm M, Borer J, Ford I, et al. Heart rate at baseline influences the effect of ivabradine on cardiovascular outcomes in chronic heart failure: analysis from the SHIFT study. Clin Res Cardiol. 2013;102(1):11-22.

10. Borer JS, Böhm M, Ford I, et al. Effect of ivabradine on recurrent hospitalization for worsening heart failure in patients with chronic systolic heart failure: the SHIFT Study. Eur Heart J. 2012;33(22):2813-20. Available at: http:// eurheartj.oxfordjournals.org/content/33/22/2813. Accessed July 9, 2016

11. Arias E. United States life tables, 2010. Natl Vital Stat Rep. 2014;63(7):1-63. Available at: http://www.cdc.gov/nchs/data/nvsr/nvsr63/nvsr63_07.pdf. Accessed July 9, 2016.

12. Chamberlain AM, Redfield MM, Alonso A, Weston SA, Roger VL. Atrial fibrillation and mortality in heart failure: a community study. Circ Heart Fail. 2011;4(6):740-46.

13. Centers for Medicare \& Medicaid Services. Chronic conditions among Medicare beneficiaries. Chartbook: 2012 edition. October 2012. Available at: https://www.cms.gov/Research-Statistics-Data-and-Systems/StatisticsTrends-and-Reports/Chronic-Conditions/2012ChartBook.html. Accessed July $9,2016$.

14. Owan TE, Hodge DO, Herges RM, Jacobsen SJ, Roger VL, Redfield MM Trends in prevalence and outcome of heart failure with preserved ejection fraction. N Engl J Med. 2006;355(3):251-59.

15. Fonarow GC, Albert NM, Curtis AB, et al. Improving evidence-based care for heart failure in outpatient cardiology practices: primary results of the Registry to Improve the Use of Evidence-Based Heart Failure Therapies in the Outpatient Setting (IMPROVE HF). Circulation. 2010;122(6):585-96. Available at: http://circ.ahajournals.org/content/122/6/585.long. Accessed July 9, 2016

16. InGauge Healthcare Solutions. Physicians' Fee and Coding Guide 2014 Mag Mutual Healthcare Solutions; 2014.

17. Centers for Medicare \& Medicaid Services. Medicare physician fee schedule. April 4, 2016. Available at: http://www.cms.gov/apps/physicianfee-schedule/overview.aspx. Accessed July 9, 2016.

18. Sullivan SD, Mauskopf JA, Augustovski FM, et al. Budget impact analysis-principles of good practice: report of the ISPOR 2012 Budget Impact Analysis Good Practice II Task Force. Value Health. 2014;17(1):55-14. Available at: http://www.valueinhealthjournal.com/article/S10983015(13)04235-6/abstract?_returnURL=http\%3A\%2F\%2Flinkinghub.elsevier.com\%2Fretrieve\%2Fpii\%2FS1098301513042356\%3Fshowall\%3Dtrue. Accessed July 9, 2016.

19. National Institute of Health and Care Excellence. Ivabradine for treating chronic heart failure: costing template. NICE TA 267. November 28, 2012. Available at: https://www.nice.org.uk/Guidance/ta267. Accessed July 9, 2016. 